\title{
Cardiac rehabilitation in older adults: is it just lifestyle?
}

\author{
Tone M Norekvål (1) 1,2 Heather G Allore ${ }^{3,4}$
}

\section{INTRODUCTION}

It is well established that there are patients who are less likely to access cardiac rehabilitation (CR). They include women, those of low socioeconomic status, patients living in rural areas, ethnocultural minorities and older adults. Reflecting on Jepma et al's paper in Heart, ${ }^{1}$ we turn our focus to CR programmes for older adults. Despite CR being a class I recommendation in the European Society of Cardiology guidelines, ${ }^{2}$ there continues to be a significant underutilisation of CR in older adults. Knowledge gaps across current evidencebased practice guidelines pertain to lack of sufficient data to provide sound recommendations for older adults. This is in part due to the fact that studies on which guidelines are based enrolled a low number of older adults or included older adults with few comorbidities. ${ }^{3}$

\section{Effect of CR in older adults}

In their paper in Heart, Jepma et $a l^{1}$ investigated the effect of nursecoordinated referral to a comprehensive set of three lifestyle interventions (physical activity, weight reduction and/or smoking cessation) to usual care in older ( $\geq 65$ years) versus younger ( $<65$ years) patients with coronary artery disease (the RESPONSE-2 trial). The trial included 824 patients from 15 centres in the Netherlands. The primary outcome was the proportion of patients with improvement at 12-month follow-up in one or more lifestyle risk factors. Despite more adverse cardiovascular risk profiles and comorbidities among older patients, nurse-coordinated referral to a community-based lifestyle intervention was at least as successful in improving lifestyle risk factors in older as in younger

${ }^{1}$ Department of Heart Disease, Haukeland University Hospital, Bergen, Norway

${ }^{2}$ Department of Clinical Science, University of Bergen, Bergen, Norway

${ }^{3}$ Department of Internal Medicine, Yale School of Medicine, Yale University, New Haven, Connecticut, USA

${ }^{4}$ Department of Biostatistics, Yale School of Public Health, Yale University, New Haven, Connecticut, USA

Correspondence to Professor Tone M Norekvål, Department of Heart Disease, Haukeland University Hospital, Bergen 5021, Norway;

tone.merete.norekval@helse-bergen.no patients. Adherence in older adults was excellent, with over $87 \%$ completing the physical activity programme. In fact, older adults attended significantly more weight reduction sessions and over $71 \%$ completed the smoking cessation programme.

The effect of CR in older adults is not new. ${ }^{4}$ However, it has not reached to the forefront of clinical care. Rather, the main focus has been to have (male) myocardial infarction survivors back to work. From a health economic standpoint, this may seem logical. However, it underestimates the costs related to healthcare. New cardiac events leading to readmission to hospital and need of assistance from primary care, as well as the unpaid labour of informal caregivers, are resource-demanding and influence quality of life. In some healthcare systems the costs of home-based programmes, which are of particular relevance for older adults given challenges with transport and the burden of informal caregivers, are not covered. Therefore, implementation and dissemination across a variety of healthcare systems remain challenging.

\section{Referral, accessibility and modes of delivery}

The RESPONSE-2 trial makes important points regarding referral to secondary prevention programmes and making the programmes easily accessible. Nurse referral to secondary prevention programmes performed in a systematic manner can be a first step to address the suboptimal uptake of CR. However, authority to refer to CR is dependent on country and healthcare system. Further, the mode of delivery and the setting are of importance. CR has over time evolved from a single-component exercise training programme into a comprehensive lifestyle programme targeting traditional risk factors delivered through group-based sessions. However, the setting (centre-based vs home-based, or a combined model) is especially relevant to older adults. Group-based CR may indirectly address social isolation, while the modes of delivery of some components such as the use of mobile health applications and internet-based training for e-cardiac rehabilitation (eCR) are an innovative approach ready to be tested even among the oldest adults. For older adults with barriers to attending groupbased setting, eCR may provide an avenue to social connection. eCR requires a certain level of e-health literacy and may not be applicable for those with cognitive impairment or visual impairments. Large observational studies are under way to map out the level of e-health literacy and use of devices and technologies in real-world coronary artery disease populations, including older adults. ${ }^{5}$ Using internet-based programmes combined with direct contact follow-up showed a high completion rate in RESPONSE-2. ${ }^{1}$

\section{Targeting frailty and multimorbidity}

The RESPONSE-2 trial highlights that it is time to act. However, it should be noted that those $\geq 65$ years in the trial were fairly healthy, with about 55\% having no known history of cardiovascular disease and only about $28 \%$ with a history of dyslipidaemia. In fact, among those $\geq 65$ years, only $66 \%$ were eligible for weight reduction, $21 \%$ eligible for a physical activity programme and a mere $13 \%$ eligible for the smoking cessation programme. Even with such low proportions eligible for each CR component, among those $\geq 65$ years, there were meaningful effects of weight reduction and positive effect estimates for physical activity and smoking cessation, which were diluted by those ineligible. If Jepma et $a l^{1}$ had performed an 'as treat' analysis of those eligible, it is likely they would have seen a larger effect and tighter CI for each of these CR components. In real-world populations of older adults, it is likely that moving beyond traditional risk factor management is a path forward. The older adult population is very heterogeneous with respect to their medical, physical function, brain health and social factors. Chronological age does not always correspond with health status. For those in poor health, issues brought on by multiple coexisting conditions and posthospital deconditioning deserve attention. Such programmes are rare in everyday $\mathrm{CR}$ practice.

There is a possible continuum of CR care from the traditional secondary prevention programme to the programme tested in the RESPONSE-2 trial, and further to an array of components addressing medical, physical functioning, brain health and social vulnerability factors. Tailoring traditional CR components as well as extending the array 


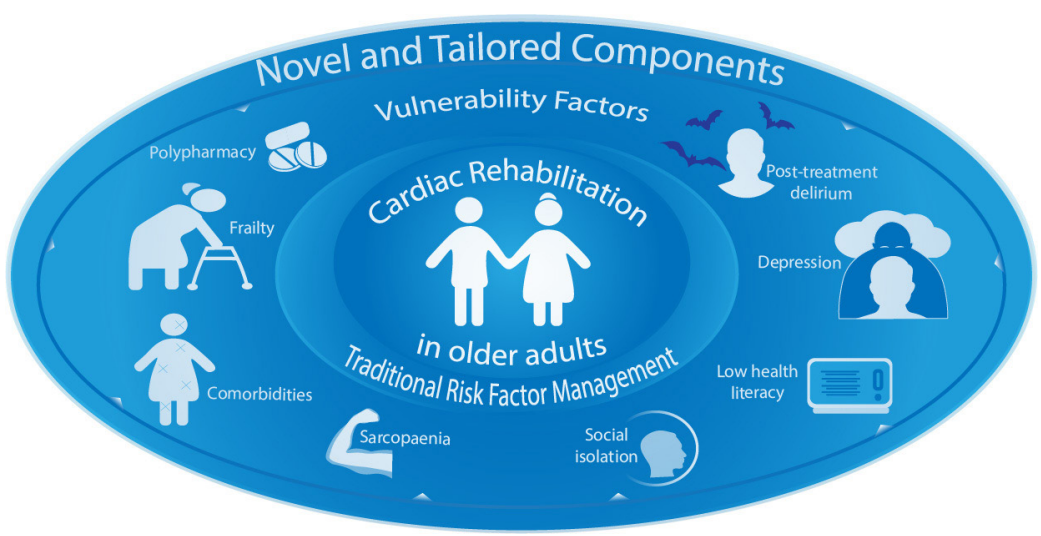

Figure 1 Moving beyond traditional cardiac rehabilitation programmes in multimorbid older adults with functional decline by adding novel and tailored components targeting vulnerability factors.

of components for the complex older patient follow how clinical care is delivered. That is, the patient receives a comprehensive assessment, and only the conditions present, which may be modified through a therapy or other interventions, are treated with components (figure 1). For example, for patients with polypharmacy there could be a medication review, for patients with sarcopaenia there could be weight bearing and/or balance exercises and nutrition optimisation, and for patients with brain health deficits, such as depression, there could be a variety of therapeutic approaches dependent on the diagnosis and severity. Recognising post-treatment delirium and cognitive impairment in some patients will highlight the need to include informal caregivers into the CR programme.

Frail older adults are generally excluded from CR programmes and trials under the notion that older adults do not have sufficient exercise capacity. Sarcopaenia as part of posthospital deconditioning is common, and loss of muscle mass per day of bed rest is significant. Thus, CR components, such as physical activity, which may delay frailty and reduce sarcopaenia, should be encouraged and used as a measurable outcome. However, as called for by European CR leaders, we need to better understand whether exercise-based CR may change frailty status in cardiovascular patients. ${ }^{6}$ There is a need for large, sufficiently powered, exercise-based CR trials also targeting older adults in order to fill this knowledge gap.

\section{WAY FORWARD}

There is a paucity of data on the impact of diagnostic and therapeutic interventions on key outcomes that are particularly important to older patients, such as quality of life, physical function and maintenance of independence. ${ }^{3}$ The SILVER-AMI study enrolling 3000 patients $\geq 75$ years showed that functional mobility was the strongest predictor of 30-day readmission-a variable previously not included in readmission risk models. ${ }^{7}$ Adding to these measures to real-life coronary artery disease populations, the CONCARD ${ }^{\text {PCI }}$ study $^{5}$ will expand these findings by allowing for comparisons across all age groups and including patient-centred outcomes pertinent to older adults. Both the SILVER-AMI and CONCAR$D^{\mathrm{PCI}}$ studies lay foundations for novel CR interventions for older adults. The eligible population for CR is greying, as is the general population, and more complex patients will require novel and tailored approaches in CR and cardiac care (figure 1).

\section{Take home message}

The time to include cardiac rehabilitation (CR) as a first-line follow-up treatment for older adults in cardiac care is overdue. The RESPONSE-2 trial adds to the evidence base on older adults receiving benefits at the same level as younger patients by showing positive effect estimates and strong adherence among older adults randomised to weight reduction, physical activity and smoking cessation components of traditional CR. CR programmes may be expanded to include evidence-based practices to modify additional vulnerability factors of the complex older adults in a tailored manner. Given the mix of medical, physical, brain health and social vulnerability factors, a tailored CR programme is timely. For some patients, their informal caregivers may play an important role in their adherence to CR programmes; therefore, we need to rethink CR for older adults. Such opportunity for clinical practice-and for research-to have impact on cardiac care should not go unrecognised.

Acknowledgements The authors are grateful for the assistance provided by Marie Hayes in the development of the figure.

Contributors TMN conceived and wrote the first draft of the manuscript. HGA provided input to the intellectual content and revised the manuscript critically.

Funding TMN is supported in part by a Western Norway Health Authority research grant (grant no 911870). HGA is supported in part by the NIH/NIA (R01 AG047891, R33 AG057806 and P30 AG021342).

\section{Competing interests None declared.}

Patient and public involvement Patients and/or the public were not involved in the design, or conduct, or reporting, or dissemination plans of this research.

Patient consent for publication Not required.

Provenance and peer review Commissioned; internally peer reviewed.

\section{(0) OPEN ACCESS}

Open access This is an open access article distributed in accordance with the Creative Commons Attribution Non Commercial (CC BY-NC 4.0) license, which permits others to distribute, remix, adapt, build upon this work non-commercially, and license their derivative works on different terms, provided the original work is properly cited, appropriate credit is given, any changes made indicated, and the use is non-commercial. See: http:// creativecommons.org/licenses/by-nc/4.0/.

(C) Author(s) (or their employer(s)) 2020. Re-use permitted under CC BY-NC. No commercial re-use. See rights and permissions. Published by BMJ.

$$
\text { A) Check for updates }
$$

To cite Norekvål TM, Allore HG. Heart 2020;106:1035-1037.

Published Online First 16 April 2020

\section{SPlinked}

- http://dx.doi.org/10.1136/heartjnl-2019-316056

Heart 2020;106:1035-1037.

doi:10.1136/heartjnl-2019-316497

\section{ORCID iD}

Tone M Norekvål http://orcid.org/0000-0003-36402119

\section{REFERENCES}

1 Jepma P, Jorstad HT, Snaterse M, et al. Lifestyle modification in older versus younger patients with coronary artery disease. Heart 2020;106:1066-72.

2 Piepoli MF, Hoes AW, Agewall S, et al. 2016 European Guidelines on cardiovascular disease prevention in clinical practice: The Sixth Joint Task Force of the European Society of Cardiology and Other Societies on Cardiovascular Disease Prevention in Clinical Practice 
(constituted by representatives of 10 societies and by invited experts)Developed with the special contribution of the European Association for Cardiovascular Prevention \& Rehabilitation (EACPR). Eur Heart J 2016;37:2315-81.

3 Rich MW, Chyun DA, Skolnick AH, et al. Knowledge gaps in cardiovascular care of the older adult population: a scientific statement from the American heart association, American College of cardiology, and American geriatrics Society. J Am Coll Cardiol 2016;67:2419-40.
4 Lavie CJ, Milani RV, Littman AB. Benefits of cardiac rehabilitation and exercise training in secondary coronary prevention in the elderly. J Am Coll Cardiol 1993;22:678-83.

5 Norekvål TM, Allore HG, Bendz B, et al. Rethinking rehabilitation after percutaneous coronary

intervention: a protocol of a multicentre cohort study on continuity of care, health literacy, adherence and costs at all care levels (the CONCARD ${ }^{\mathrm{PCl}}$ ). BMJ Open 2020;10:e031995.
6 Vigorito C, Abreu A, Ambrosetti M, et al. Frailty and cardiac rehabilitation: a call to action from the EAPC cardiac rehabilitation section. Eur J Prev Cardiol 2017;24:577-90.

7 Dodson JA, Hajduk AM, Murphy TE, et al. Thirty-Day readmission risk model for older adults hospitalized with acute myocardial infarction. Circ Cardiovasc Qual Outcomes 2019;12:e005320. 